\title{
Invited commentary on ... Proposals for massive expansion of psychological therapies would be counterproductive across society ${ }^{\dagger}$
}

\author{
Michael King
}

\begin{abstract}
summary
Will an expansion of access to cognitive-behavioural therapy lead to greater happiness? Summerfield and Veale debate this question by focusing on the nature of mental distress and the best evidence for ameliorating it. Stimulating though it is, their debate left me wondering about the wider
\end{abstract}

philosophical and ethical implications behind our rush to therapy.

\section{Declaration of interest}

None.
As I read this debate an image came to mind of two boxers in the ring back-to-back, flailing punches in the air but not engaging. Although at face value the motion concerns the validity of our concepts of mental illness and whether mass cognitive-behavioural therapy (CBT) in Layard centres could be counterproductive across society, it has much wider implications. The real issues at play here are the public role of therapy, its place in society and the implications of making it into a mass marketable commodity. ${ }^{1}$

Summerfield opens in fine rhetorical form arguing that a focus on symptoms in the absence of context is misplaced and will increase the likelihood that people will regard themselves as ill rather than victims of life's vicissitudes. He claims that stress has become a catch-all justification for work absence but attributes this unwelcome trend at least in part to a (originally Thatcherite) political endeavour to massage the joblessness totals by moving people off the unemployment register and onto disability benefits. He argues that medicalising distress undermines age-old ways in which we understand and cope with the brutality of daily living and its perceived meaninglessness. However, he is not explicit about how this is done. Veale counters his arguments with a clarion call to evidence, particularly that found in published research. He thumps the diagnostic table with claims that shore up the validity of the English national morbidity surveys (of which I have been on the organising end) and the evidence base for talking therapies. He quite correctly places CBT in its context, namely the patient, their beliefs and their world.

All this is eminently sensible but I felt it failed to come to grips with the dilemmas at the heart of the debate. First, what is the right relationship of publicly available psychotherapy to law, politics, ethics and religion? Second, do psychiatric diagnoses and CBT divert us from a fuller grasp of what it is to live a life that for many has little meaning, is frequently unjust and ends in death? Throughout history people have traditionally used spiritual or religious belief to steer them through such existential mysteries. Even early Enlightenment figures did not ditch God in their rush to rationality. However, our current crop of proselytising atheists (e.g. Richard Dawkins) completely misses the point about religion by condemning as plain silly its explanations for the world in which we live. Probably all except the most fundamentally religious agree with that. Religion is about much more than explanation; rather it concerns the sacred and a sense of meaning that goes beyond our current perception and understanding. Where does this fit in to the secular world of CBT? How will mass

†See pp. 326-330, this issue. therapy, which is deeply and inextricably ethical in character, function in that complex mix of culture, ethnicity, religion and morals which is British society?

The empiricist focus rides unchallenged in Layard's proposals and there is little surprise in that. However, as Veale also stresses, CBT is far more than a treatment of symptoms in that it grapples with how one regards oneself in the world of relationships, work and leisure. Summerfield appears to argue that CBT is some kind of technical innovation in a brave new world. In fact, it has a history reaching back in one form or other to Buddhist texts, the Hebrew Scriptures (particularly Proverbs) and Enlightenment thought. The Scottish Enlightenment philosophers Francis Hutcheson and Adam Smith stressed the natural links between inner impulses (virtuous or otherwise), behaviour, rationality and happiness. ${ }^{2}$ Smith in particular wrote about the impartial spectator' as one half of an internalised divided self that approved or condemned the conduct and character of the whole. ${ }^{3}$ This natural moral psychology was a forerunner to Beck's 'distancing' from thoughts or the current fashion for a mindful approach to cognition. Thus, there is little that is new in modern CBT, apart from its call for evidence of efficacy. However, debate over the public role of psychotherapy is very new; what is argued here is its application as a fix for the (distressed) masses.

I enjoyed Summerfield's style; after all, few would disagree that we have become far too comfortable with those symptom collections that we call diagnoses. However, like Veale, I was uneasy with what he might propose instead of Layard. Very little, as far as I could see, apart from the tiring business of keeping one's upper lip stiff. Nor was I convinced that Layard's vision for CBT will make the British population into a mass of work-shy, complaining layabouts who cannot cope. Such a view patronises the British psyche.

As I said at the outset, I believe this debate leaves untouched many of the conundrums inherent in greatly expanding access to CBT in Britain. After all, who says psychotherapy is inherently a good? Despite the science, CBT like all psychotherapy is a valueladen, social construction that has most meaning in Western societies. How do we decide whether a behaviour is right, a personality characteristic worthy, a therapist virtuous or a goal of therapy good? ${ }^{4}$ Could depression be a sign of something inherently awry with a person's place in the world rather than faulty thinking? And on what basis is someone's thinking faulty in the first place? Recourse to impressive treatment protocols of the sort Veale describes often shelters us from the ethics and values that are inevitably part and parcel of expanding access to psychotherapy so dramatically. This I think is what bothers 
Summerfield but not Veale. And so, what lies at the heart of this debate is the balance between the extreme individualism seen in the expansion of CBT on this scale and broader ideas about citizenship that take a more complex approach to the place of individual happiness in the world. ${ }^{5}$ Will Layard's vision be counterproductive across society? Clearly we shall have to wait and see.

Michael King, MD, PhD, Department of Mental Health Sciences, Royal Free and University College Medical School, Hampstead Campus, Rowland Hill Street, London NW3 2PF, UK. Email: m.king@medsch.ucl.ac.uk

References

1 Browning DS, Evison IS. Does Psychiatry Need a Public Philosophy? Nelson Hall, 1991.

2 Porter R. Enlightenment: Britain and the Creation of the Modern World. Penguin, 2000.

3 Smith A. Theory of Modern Sentiments. A Millar, 1759.

4 Tjeltveit AC. Ethics and Values in Psychotherapy. Routledge, 1999.

5 Bellah RN. The Good Society. Knopf, 1999.

\section{psychiatry in pictures}

\section{Alexandra Reinhardt 1960-2004. River and Red Butterfly}

Text by Dr Alexandra Pitman

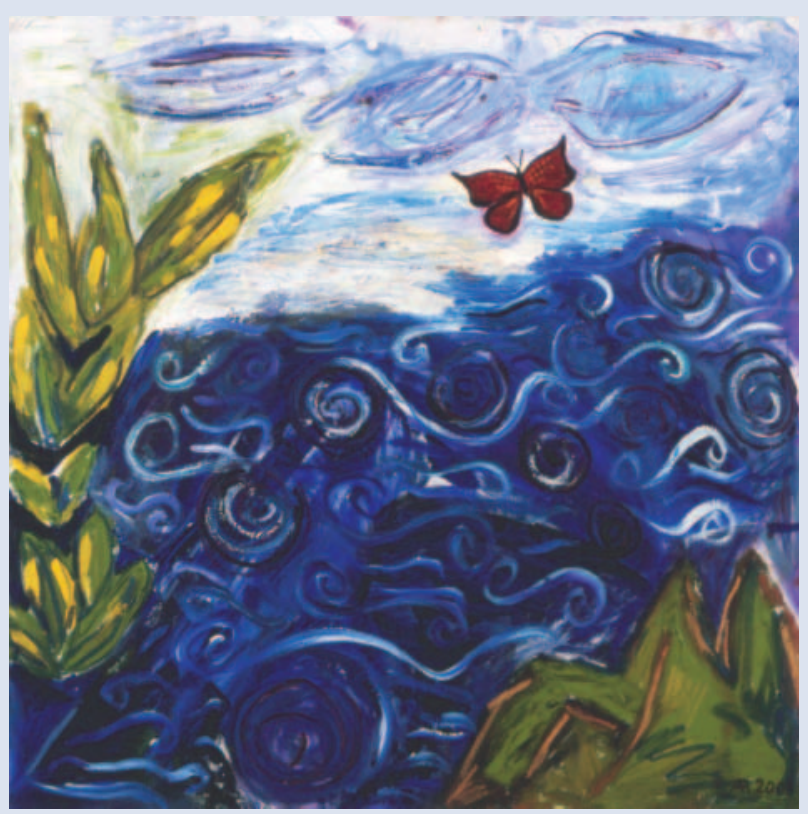

Diagnosed with Diamond-Blackfan anaemia and congenital deafness as an infant and sentenced to years of transfusions, admissions and medications, the artist Alexandra Reinhardt initially used art as a form of therapy. During the long hours of transfusions she would vent her frustration by making collages out of the equipment used: giving sets, syringes and blood transfusion bags. In her twenties she was the first deaf student at the Chelsea College of Art and continued to use the visual arts and poetry as a means of expressing the impact of her condition.

Her lifelong relationship with hospitals intensified as her illness worsened and at the age of 32 she was diagnosed with depression. What is striking about her later work is the lack of any correlation between her clinical state and the mood of her work. When her body was at its weakest, her paintings changed to express a positive energy and vibrancy at odds with her extreme frailty, as shown in the image chosen here.

Following her death from septicaemia at the age of 43 her family established a scheme in her name, designed to bring art and creative activity into hospitals. This reflected her wish to create more uplifting environments in hospitals for patients, relatives and staff. The catalogue of her own work reflects the depths of her suffering as well as her humour, vitality and force of personality. For patients on psychiatric or any other wards the question of whether art in hospitals should be joyful to be truly uplifting remains a subject for debate.

The Alexandra Reinhardt Memorial Award is a $£ 10000$ annual prize awarded by Paintings in Hospitals and funded by the Max Reinhardt Charitable Trust. The winning artist works on a programme of creative activities with patients, staff and visitors in a National Health Service hospital and is commissioned to create a major work of art for permanent display at that site. In addition a further piece is produced for the Paintings in Hospitals Collection which will be available to borrow by other hospitals in the UK. For further information please contact Helen Bonar at Paintings in Hospitals +44 (0)207 407 3222; mail@paintingsinhospitals.org.uk; www.paintingsinhospitals.org.uk. More information about Alexandra can be found at www.alexandrareinhardt.org.uk 